\title{
Percepções de crianças do Rio de Janeiro sobre as representações raciais: notas de campo
}

\section{Thaís de Carvalho}

Mestranda no Programa de Pós-Graduação em Comunicação Social da Pontifícia Universidade Católica do Rio de Janeiro (PUC-Rio).

E-mail: thaiscarlo@gmail.com
Resumo: Este artigo visa a principiar uma análise da reação das crianças ao predomínio de representações positivas brancas na mídia. Através do conceito de discriminação racial como trauma cultural e do trabalho de diversos autores sobre o colorismo no Brasil, é feita uma contextualização dos comentáriows simbolicamente violentos dos pequenos nas escolas. $O$ artigo também aponta algumas estratégias de construção do discurso e políticas públicas que começam a aparecer na tentativa de resolver esse problema. $O$ trabalho é parte de minha pesquisa de mestrado sobre a violência nas interações cotidianas das crianças, para a qual realizei trabalho de campo em duas escolas de contexto socioeconômico diferente na cidade do Rio de Janeiro.

Palavras-chave: Crianças; Escola; Representação; Recepção; Racismo.

Perceptions of children from Rio de Janeiro, Brazil, about racial representation: notes from the field

Abstract: This study aims to start an analysis of children's reaction to the dominance of positive White representation in media. Through the usage of the concept of racial discrimination as a cultural trauma and the work of various authors on colorism in Brazil, there is a contextualization of children's symbolically violent discourses in schools. The article also points out some strategies of discourse building and policies that are beginning to be made in an attempt to address this matter. The work is part of my Master's research about the violence in children's daily interactions, for which I have done fieldwork in two school of different social and economical profiles in the city of Rio de Janeiro, Brazil.

Keywords: Children; School; Representation; Reception; Racism. 
Introdução

S., uma boa aluna, quando parabenizada por suas notas, diz com orgulho: - Quando eu crescer eu quero ser médica. J., sentada a seu lado, debocha da amiga: - Ih, garota, você já viu médico preto?

(Diálogo entre duas meninas de 8 anos durante o almoço em escola municipal no Complexo da Maré)

Este trabalho buscará discutir de que forma as representações raciais afetam as percepções das crianças sobre elas mesmas. As questões aqui levantadas foram inspiradas em meu trabalho de campo em duas escolas, como parte de minha pesquisa de mestrado. A seleção dos locais de pesquisa foi feita de forma a contemplar diferentes infâncias no Rio de Janeiro. A primeira escola era privada e de mensalidade elevada e se localizava no bairro da Tijuca; a segunda, pública e municipal, ficava em uma das favelas do Complexo da Maré. Pretendo sinalizar neste artigo que, apesar dos esforços jurídicos, educacionais e políticos para combater atitudes racistas, as crianças continuam entendendo a branquitude como um espaço de privilégios de acordo com o que observam em seu cotidiano e na mídia.

A faixa etária dos alunos que acompanhei ao longo desses quatro meses de campo era de 8 a 10 anos e cada escola possuía um perfil de aluno diferente. $\mathrm{Na}$ Tijuca, a turma de 20 alunos era majoritariamente branca e masculina, com apenas 4 alunos não brancos e 6 meninas. Na Maré, o perfil se invertia. Lá a turma tinha em média 25 alunos - alguns saíram da escola durante a pesquisa -, dos quais apenas 3 eram brancos e mais da metade eram meninas. Não pude escolher os grupos de crianças com os quais trabalhei. Foram as diretoras de cada instituição que me indicaram às turmas conforme o que achavam adequado. $A$ noção da "turma ideal" também variava: na Tijuca, a diretora sugeriu este grupo de alunos porque eram crianças "falantes e criativas", "interessantes para minha pesquisa", e a professora responsável por elas era ótima. Na Maré, a turma foi escolhida por ser a que estava mais avançada na alfabetização e porque tinha os alunos mais "dóceis" na faixa etária estudada (a palavra "dóceis" foi usada pela professora responsável pelas crianças).

O diálogo que apresenta este trabalho e outros ao longo do texto visam a mostrar que as crianças são capazes de perceber lugares sociais racializados e de se sentir limitadas por eles. Portanto, apesar dos avanços políticos e jurídicos no combate a atitudes racistas, ainda é necessário discutir as formas de assimilação e de naturalização do preconceito de cor no Brasil. Um número crescente de autores, como Sodré (2000), Sovik (2004), Araújo (2004), Gomes (2008), Soares (2012) e Schucman (2012), vem combatendo a ideia de harmonia racial que é tão comumente difundida como qualidade do ser brasileiro. Em seu lugar, apresentam as duras estratégias de operação do racismo velado. Esse texto propõe enriquecer o debate trazendo a discussão da representatividade para a área da socialização infantil e explicitando, através das vozes das crianças, como as expectativas sobre a negritude e a branquitude são incorporadas a suas identidades.

A noção de trauma cultural no contexto do Brasil: a relevância do debate sobre a representatividade

O ambiente urbano desigual do Rio de Janeiro revela rapidamente as discrepâncias entre brancos e não brancos, inclusive, entre diferentes tons de pele. Considerando-se a história do país, de colonização portuguesa e escravidão africana, é possível entender como essas desigualdades foram forjadas e a que 
interesses serviam. Ainda é frequente, no entanto, que os preconceitos raciais sejam disfarçados por justificativas socioeconômicas (SOVIK, 2002), apesar da óbvia vantagem histórica da população branca sobre os demais espectros de cores que compõem o Brasil.

Carter (2007) defende que para entender o estresse pós-traumático associado ao racismo é necessário considerar as diferentes experiências possíveis de segregação racial: a discriminação (relativa às formas muitas vezes não intencionais de manter ou delimitar distâncias entre indivíduos de diferentes fenótipos), o assédio e o assédio discriminatório. Para tratar dos relatos das crianças no campo, limitarei o escopo deste artigo à discriminação, em especial quando relacionada à noção de trauma cultural e de identidade.

A noção de trauma cultural, conforme trabalhada por Eyerman (2003), considera que o processo traumático não está necessariamente condicionado à vivência de um determinado evento. $O$ trauma cultural seria experimentado através da lembrança posterior e negociada - ou seja, a forma como a memória em torno do evento é construída é um processo fundamental para esse conceito. A memória de que ele fala não é aquela individual, mas o discurso de pessoas conversando juntas sobre o passado. Eyerman fala do racismo como evento traumático a partir do contexto dos Estados Unidos, onde a abolição sem um projeto real de integração das populações afrodescendentes representou um trauma cultural porque demandou uma reavaliação do passado e de seu significado para as identidades individuais e coletivas - uma vez que a categoria de "escravo", que determinava a diferença entre os direitos civis de negros e brancos, deixou de existir, mas a discriminação foi perpetuada. (Ibid.: 24).

Apesar de haver diversas particularidades no processo abolicionista americano em relação ao Brasil, a noção de trauma cultural se aplicaria a nosso contexto porque, assim como nos Estados Unidos, aqui também existe um histórico evidente e persistente de discriminação racial, que sobrevive às mudanças políticas e sociais do país. Mais ainda, extrapolando a noção de trauma cultural associado à memória da escravidão, é possível argumentar que esta se amplia para o momento presente enquanto a discriminação de cor continuar a interferir nas relações sociais no país.

Para aproximar o trauma cultural da realidade das crianças nas escolas que pretendo relatar, é essencial entender a relação da memória coletiva (como discurso narrativo) com a identidade individual. Em Ethics of identity, Appiah (2005: 68) explica a formação da identidade social como algo construído sobre histórias maiores:

Através da minha identidade eu encaixo minha história de vida em certos padrões - catequese na puberdade para uma identidade religiosa, estabilidade aos trinta para uma identidade profissional - e também dentro de outras histórias maiores; por exemplo, de uma tradição religiosa ou de uma raça.

Em um país desigual e discriminador, reconhecer-se como não branco implica entender-se pertencendo a um lugar social de exclusão. 0 diálogo das alunas da Maré no início desse texto é um exemplo disso - pois, se as duas nunca viram uma médica negra, podem concluir que não é possível sê-lo. Porque a narrativa da identidade individual se relaciona com narrativas maiores, como argumenta Appiah, é justificável que uma criança se sinta limitada pela escassez de representação étnico-racial em determinadas carreiras profissionais, na mídia e na História.

Para abordar o tema do racismo no Brasil é necessário, antes, descartar o mito da miscigenação harmoniosa, frequentemente associado à imagem nacional. $\mathrm{A}$ mistura de raças, que de fato foi enaltecida como parte da identidade brasileira, 
servia ao objetivo de clarear gradualmente a população, pautado por um ideal estético e cultural europeu (SODRÉ, 2000). Durante o auge do racismo cientificista no final do século XIX, a elite brasileira se preocupava com o grande contingente de negros no país, o que, a seus olhos, significaria um destino nacional trágico a longo prazo. Daí surgiu o ideal de eliminar a negritude no Brasil por meio do clareamento gradual da população - por exemplo, pelo estímulo à imigração europeia. O branqueamento ainda é forte no imaginário popular e é comum que não brancos busquem associar-se às redes brancas (DENNISON, 2013).

O fato de os estereótipos negativos estarem diretamente associados à cor e à raça negra fez também com que os brasileiros mestiços e grande parte da população com ascendência africana, de maneira geral, não se classificassem como negros, gerando um grande número de denominações para se designar as cores dos não brancos, como: moreno, marrom, escurinho etc. (SCHUCMAN, 2012: 44).

Em estudo realizado pelo IBGE em 2008, 96\% da população brasileira com quinze anos ou mais afirmaram saber definir a própria cor ou raça. Dessa porcentagem, $49 \%$ se declararam como brancos, o que equivale a dizer que $51 \%$ seriam não brancos. Quando perguntados sobre suas ascendências, apenas $1,31 \%$ dos brasileiros que afirmaram saber definir sua cor ou raça declarou ser de origem clara (somando-se aqui os percentuais das categorias "clara", "alemã" e "italiana" oferecidas pelo IBGE). Portanto, a população brasileira segue sendo composta majoritariamente por não brancos e mestiços. No entanto, a julgar pelas representações midiáticas, pode parecer ser justamente o contrário.

A representação seletiva da população na mídia tem um efeito doutrinador sobre os espectadores, principalmente as crianças, indicando lugares sociais determinados pela cor de pele. Os trabalhos de Araújo (2004) e Gomes (2008) mostram como os papéis subalternos nas novelas e no cinema são com frequência interpretados por atores negros. Em 2015, na cerimônia do Emmy, a atriz Viola Davis também discursou sobre a questão da representatividade, afirmando que "a única coisa que separa mulheres de cor de qualquer outra é a oportunidade.

${ }^{1}$ No original: "The only thing that separates women of colour from anyone else is opportunity. You cannot win an Emmy for a role that is simply not there".

${ }^{2}$ A princesa e o sapo (2009).

${ }^{3} \mathrm{O}$ autor fala principalmente das telenovelas Gabriela (1975), A cabana do Pai Tomás (1969) e Escrava Isaura (1976), em que atores brancos foram escalados para fazer papéis de negros/mestiços.
Você não pode ganhar um Emmy por um papel que simplesmente não existe" ${ }^{1}$ (VIOLA DAVIS..., 2015).

No que concerne à programação infantil de televisão e cinema, até recentemente a maioria dos programas dedicados às crianças no Brasil era apresentada por mulheres brancas e loiras - o exemplo mais marcante é a Xuxa e seu séquito de Paquitas. Crianças assistem a desenhos animados em diversos canais, quase sempre retratando heróis e princesas como personagens brancos e de olhos e cabelos claros (HURLEY, 2005). Embora a Disney tenha tentado quebrar essa tendência, apresentando a primeira animação com uma princesa negra em 2009, o filme em questão recebeu um investimento muito menor do que os outros do mesmo gênero e nele a princesa está a maior parte do tempo transformada em sapo ${ }^{2}$. Não há muitas referências na mídia de personagens negros com os quais as crianças possam se identificar e, quando há personagens negros, estes frequentemente estão em uma posição subalterna ou má - é o caso de Jafar, em Aladdin, e Scar, em O Rei Leão.

Com frequência o debate sobre o racismo e a representatividade são diminuídos em importância porque se assume que as escolhas de personagens são feitas por mérito e não por cor de pele - é o argumento de muitos diretores entrevistados por Joel Zito Araújo em A negação do Brasil (2004)3. No entanto, a determinação estética eurocêntrica que norteia a contratação de atores é clara, principalmente quando analisamos em conjunto as escolhas estéticas nas animações. É importante entender que, por mais automáticas que sejam essas decisões de casting, elas precisam sem problematizadas porque influenciam na formação de identidade dos espectadores. 


\section{O lugar privilegiado do branco na mídia e os afetos a ele vinculados}

Erny (1981: 11) chama de educação informal o processo por meio do qual a criança aprende como a sociedade é por observação - em oposição à educação formal, aquela em que é ensinado aos pequenos como a sociedade deveria ser (por intermédio da escola e das lições morais dos pais e da igreja, por exemplo). A mídia pode ser considerada um espaço de educação informal, onde, pelo que é representado, vai-se moldando a visão do espectador sobre o mundo e sobre si próprio.

No Complexo da Maré, foram diversos os casos em que as crianças expressaram abertamente aversão à identidade negra. Logo em meu primeiro dia de campo, algumas meninas dividiam a turma entre fadas (do bem) e bruxos (do mal). Foram apontadas como bruxos as três crianças de cor mais escura (duas meninas e um menino). Uma das meninas ficou visivelmente triste e quis saber o porquê de não poder ser "do bem". Uma das crianças que classificavam a turma disse " $a h$, não, você é muito escura". Em outra ocasião, alguns meninos estavam desenhando e interpretando personagens de desenhos animados. S. (a menina que quer ser médica) disse para um deles "você não pode ser o Tarzan, só se for um Tarzan preto!".

Cabe ressaltar que todas as meninas da turma possuíam mochilas de princesas e bonecas loiras. T., de 8 anos, trouxe uma boneca para a escola com muito zelo, brincando de cuidar dela de vez em quando ao longo da aula. Mostrou-a para mim com muito orgulho dizendo que era um presente de aniversário de seu pai "para brincar de filhinha". L. debochou da amiga, dizendo que a boneca era branca e não podia ser "filha de mãe preta". T. ficou chateada e guardou a boneca. Semanas mais tarde, a mesma cena se repetiu, agora com L., que tinha ganhado um par de bonecas do pai por ocasião do nascimento de sua irmã. Os dois brinquedos eram idênticos, brancos e de olhos azuis. Dessa vez foi J. quem debochou da situação, dizendo que as bonecas não podiam ser L. e a irmã porque elas eram pretas. A resposta de L. foi um pouco mais tranquila do que a de T.: "eu sei, é só de brincadeira".

Para o dia das mães, a escola preparou ilustrações que as crianças deveriam pintar e levar para casa. A figura materna tinha os cabelos compridos e lisos, era magra e de rosto fino, os olhos sem cor definida para serem pintados pelas crianças. Das 22 crianças presentes em sala naquele dia (o número variava com frequência), 9 pintaram a mãe como branca e loira, 7 pintaram como branca e ruiva, 5 pintaram como branca e de cabelos castanhos e 1 pintou todo o desenho em tons de azul. Nos desenhos, a questão racial apareceu outras vezes. As meninas costumavam me escrever cartas e fazer desenhos para eu levar para casa. As crianças que desenhavam eram sempre brancas e loiras, quase sempre com o cabelo preso em rabo de cavalo com um lacinho rosa. S. nos desenhou de mãos dadas em um campo aberto, as duas de cabelo loiro e da mesma altura. Só compreendi sua intenção quando perguntei quem eram as pessoas no desenho e ela escreveu sob as personagens a legenda "S. e Thaís".

Em um espaço de desigualdade tão notória, a criança não branca percebe que Ihe são negados certos benefícios e assimila desde cedo que sua desvantagem social tem a ver com sua cor de pele. David Milner (1975: 140), em seu trabalho com crianças negras britânicas na década de 1970, descreveu de que forma os conflitos identitários podem assolar minorias desprivilegiadas:

Um dos problemas centrais que a criança negra enfrenta é o de estabelecer para si mesma uma identidade viável. Ela é socializada em um mundo em que o valor da sua cor de pele é altamente negativo. Seus pais e outros comunicamIhe que uma realidade em que seu grupo é desvantajoso e desvalorizado, e é condenado a viver em um ambiente material inferior. Mais tarde, esta criança encontrará o preconceito direto, através da verdadeira rejeição social [...]. 
Uma vez que a criança não pode aceitar inequivocamente um importante aspecto de si mesma - sua raça -, parece inevitável que ela experimente um agudo conflito identitário.

Embora os espaços formais de educação - a família, a escola etc. - não possam interferir no que a criança apreende da realidade em que está inserida, é importante que ofereçam vias de questionamento dessas representações e, quando possível, repensem as formas como elas próprias moldam e perpetuam as memórias coletivas.

\section{O papel da escola no fortalecimento das identidades}

A História é a disciplina que seleciona, molda e representa os acontecimentos passados. Por essa razão, seu ensino carrega a responsabilidade sobre a construção da identidade dos alunos, pois unifica a comunidade através da perpetuação de uma memória coletiva - "a forma como um evento é lembrado está intimamente ligada à forma como ele é representado" (EYERMAN, 2003: 12). A seção anterior abordou o ensino informal de lugares sociais racializados, através da mídia e da observação do cotidiano da cidade. Cabe ressaltar agora o papel do ensino formal no enfrentamento do racismo estrutural.

A forma como a história é contada nas escolas, representada na mídia e no imaginário coletivo brasileiro também nos ensina a ver diferentes significados para diferentes cores de pele (SCHWARCZ, 2012). Muitas expressões carregam a marca do racismo brasileiro, como "mercado negreiro", "a coisa tá preta" (sic), "denegrir", entre outras. Com frequência, inclusive, a palavra "negro" foi utilizada para substituir a palavra "escravo" nos livros de história - dando a entender que as duas seriam sinônimas. Essas construções discursivas também transmitem uma conotação negativa sobre a negritude e têm sido combatidas pelos movimentos sociais.

$\mathrm{Na}$ escola da Tijuca, de pedagogia construtivista, o tema da escravidão apareceu como tópico curricular durante minha pesquisa. Estive presente em uma aula em que as crianças escreveram coletivamente um texto sobre a visita que fizeram no fim de semana ao Cais do Valongo, experiência que contribuiu positivamente para repensar a construção de identidades na infância. A visita ao Cais do Valongo foi uma atividade de campo que serviu para apresentar às crianças o porto que recebia os escravos no Rio de Janeiro, o passado do Brasil colonial e escravocrata, e parte da herança cultural africana (as crianças também assistiram a um ritual do Candomblé no mesmo dia).

A escrita coletiva funciona com as crianças sentadas em roda no chão junto com a professora, que porta uma caneta e um pedaço grande de cartolina. A professora dá algumas orientações sobre o que deve entrar no texto ("Onde fomos? O que vimos lá?") e ouve a sugestão dos alunos que levantam o dedo para falar. As sugestões vão sendo votadas pelas próprias crianças com sugestões da professora ("Gostei da frase do A., o que vocês acharam?"). Quando a maioria concorda com a escolha de palavras, a professora registra a frase no papel. No final, todas as crianças assinam o cartaz, que será pendurado na sala ou no corredor para que possa ser consultado em debates futuros sobre o tema.

${ }^{4} \mathrm{Na}$ escola em questão, as crianças costumavam brigar muito e por isso havia um combinado feito em "assembleia" (o nome dado a essas reuniões em roda no chão) e pendurado na parede que lembrava às crianças que as palavras que dizemos podem machucar o outro, e por isso devemos ter cuidado com o que dizemos.
Nessa experiência, vale ressaltar que uma discussão interessante sobre o poder das palavras partiu das próprias crianças - tendo aparecido antes, em outros contextos, inúmeras vezes em sala de aula ${ }^{4}$. Ao falar sobre a origem do Cais do Valongo, B. sugeriu a seguinte frase para o texto: "Foi o porto onde chegavam os africanos". A professora perguntou se todos concordavam. A. sugeriu que trocassem "africanos" por "escravos", porque achava importante deixar claro que os africanos não vinham por legítima vontade. L. complementou: "Acho melhor botar 'pessoas escravizadas' porque ninguém nasce escravo, eles nasceram 
livres e foram forçados a trabalhar como escravos pelos europeus". As crianças concordaram e essa foi a frase escolhida para o texto final.

Apesar de todo o cuidado com as palavras que as crianças exibiram na redação do texto coletivo, no tempo livre daquele mesmo dia vieram me perguntar quem eu achava que era o mais branco na sala, pedindo que eu organizasse um grupo de cinco alunos por escala de cor de pele. Perguntei por que estavam interessados nessa brincadeira e elas responderam que queriam saber "quem tem mais sangue de europeu". A "brincadeira" sugere que apesar de todo o cuidado pedagógico - que de fato surte efeito no ambiente disciplinado da sala de aula -, a discriminação opera de formas diversas e precisa ser combatida e debatida em diferentes esferas sociais.

\section{Conclusão}

Os relatos de campo apresentados ao longo deste trabalho buscaram mostrar, através de manifestações das próprias crianças, a relevância e a urgência dos debates sobre a representatividade e sobre o racismo no Brasil. Bourdieu e Passeron (1990) apontaram, desde a década de 1970, como a reprodução de lugares sociais é naturalizada em diversas esferas da educação. Portanto, é sabido que a mudança social não se dá senão por meio do questionamento constante e de uma postura politicamente ativa.

Em 2002, o Projeto de Lei 4.370/1998 foi aprovado pela Comissão de Defesa do Consumidor garantindo um elenco mínimo de $25 \%$ de atores afro-brasileiros em programas de TV e peças de teatro e de $40 \%$ em propagandas. Ainda assim, grande parte do entretenimento infantil é importada e não há política equivalente para animações. Este trabalho argumenta a favor de políticas inclusivas na mídia, nacional e internacionalmente, uma vez que a falta de representatividade pode ameaçar a autoestima da criança não representada.

Crianças que forem socializadas direta ou indiretamente para a discriminação de cor vão encontrar propagandas racistas com ou sem leis de incentivo à representação étnico-racial (BUCKINGHAM, 2010). Isso porque o próprio universo em que estão inseridas está repleto de outros fatores informais e não legisláveis que colaboram para a formação de conceitos identitários - dizem respeito à observação de uma sociedade desigual e ao reconhecimento de privilégios associados à cor da pele, como a seção anterior exemplificou.

O reconhecimento de que políticas de incentivo à representatividade não bastam por si sós não justifica sua negligência. Pelo contrário, reforça que a regulação é o que pode ser feito para transformar a longo prazo os espaços formais de aprendizagem e a mídia, contribuindo para uma mudança social em larga escala. No entanto, é necessário fundar uma abordagem antirracista em várias frentes, deixando um espaço aberto para o debate das desigualdades e a renovação da consciência social, incentivando a representação nas telas, mas também tendo um cuidado diário e individual com as posturas em sociedade e com as palavras e as expressões idiomáticas que, assim como ensinamos às crianças, podem ferir o outro.

\section{Referências}

APPIAH, K. A. The ethics of identity. New Jersey: Princeton University, 2005.

ARAÚJO, J. Z. A negação do Brasil: o negro na telenovela brasileira. São Paulo: Senac, 2004.

BOURDIEU, P.; PASSERON, J. C. Reproduction in education, society and culture. London: Sage, 1990. 
BUCKINGHAM, D. Children's media rights. In: After the death of childhood: growing up in the age of electronic media. Cambridge: Polity, 2010.

CARTER, R. T. Racism and psychological and emotional injury: recognizing and assessing race-based traumatic stress. The Counseling Psychologist, London, v. 35, n. 1, p. 13-105, jan. 2007.

DENNISON, S. Blonde Bombshell: Xuxa and notions of whiteness in Brazil. Journal of Latin American Cultural Studies, [s.I.], v. 22, n. 3, p. 287-304, 2013.

ERNY, P. L'ethnologie de l'éducation. Paris: PUF, 1981.

EYERMAN, R. Cultural trauma: slavery and the formation of African American identity. Cambridge: Cambridge University, 2003.

GOMES, I. B. A. A ameaça simbólica das cotas raciais na mídia brasileira: o negro nas telenovelas. São Luís: UFMA, 2008.

HURLEY, D. Seeing white: children of color and the Disney Fairy Tale princess. The Journal of Negro Education, New York, v. 74, n. 3, p. 221-232, 2005.

MILNER, D. Children and race. London: Penguin, 1975.

NASCIMENTO, E. L. The sorcery of color: identity, race and gender in Brazil. Philadelphia: Temple University, 2009.

SCHWARCZ, L. M. Nem preto nem branco, muito pelo contrário: cor e raça na sociabilidade brasileira. São Paulo: Companhia das Letras, 2012.

SCHUCMAN, L. V. Entre o "encardido", o "branco" e o "branquíssimo": raça, hierarquia e poder na construção da branquitude paulistana. 2012. 122 f. Tese (Doutorado em Psicologia) - Instituto de Psicologia, Universidade de São Paulo, São Paulo, 2012.

SOARES, M. A. S. Look, blackness in Brazil!: disrupting the grotesquerie of racial representation in Brazilian visual culture. Cultural Dynamics, London, v. 24, n. 1, p. 75-101, 2012.

SODRÉ, M. Claros e escuros: identidade, povo e mídia no Brasil. Petrópolis: Vozes, 2000.

SOVIK, L. Aqui ninguém é branco: hegemonia branca e média no Brasil. In: WARE, V. (Org.). Branquidade: identidade branca e multiculturalismo. Rio de Janeiro: Garamond, 2004. p. 363-386.

VIOLA DAVIS gives powerful speech about diversity and opportunity: Emmys 2015. Reprodução: YouTube - Television Academy. 20 set. 2015. (3 min), son., color. Disponível em: <http://bit.ly/1KFr670>. Acesso em: 18 jan. 2016. 